\title{
Proyección Histórica de América sobre el Pensamiento Europeo
}

\author{
Trabajo de Seminario del Curso de Historia \\ de Anérica.
}

\section{Consideraciones Generales}

El descubrimiento de América por Cristóbal Colón; los viajes sucesivos de hombres impulsados por una sed de aventura, de conocimiento y de horizontes nuevos; las conquistas de nuevas tierras, el hallazgo de tesoros imponderables; el enfrentamiento a nuevos tipos de hombres, de instituciones, de gobiernos, y a nuevas formas de vida; la lucha con una naturaleza bravía, con sorpresivas maneras de agresividad para el europeo; el resurgimiento, en fin, de un Mundo Nuevo para la mentalidad y la cultura ocidental, abrió una insospechada perspectiva para la vida y el pensamiento europeos. Fué como una tremenda convulsión que sacudió al Mundo de Occidente este singular acontecimiento de la Historia; no era por un cataclismo que sepultara una cultura - un pueblo; era por el afloramiento de un continente nuevo, desde el seno de los mares tormentosos, desde el ángulo remoto apenas soñado por visionarios e ilusos, con todo el misterio apasionante de sus fabulosas riquezas, desus maravillosas leyendas, de sus extraños habitantes, de su fauna y de su flora, que constituían una fuerza irresistible de novedad y atracción, para que los sabios, los gobernantes, los navegantes y los hombres de la calle de Europa sintieran una profunda inquietud y movilizaran su pensamiento $Y$ su acción hacia un inmenso horizonte que Colón había abierto con su formidable hazaกีa.

No fué, pués, un acontecimiento cualquiera el descubrimiento de Ámérica para el antiguo Continente. No fué un hecho histórico de carácter local, cuya trascendencia no alcanza a ensanchar el ámbito espacial de la civilización, aunque enriquezca enormemente el acervo cultural. El hallazga de América extendió imponderablemente en el ponsamiento del hombre europeo el espacio terrestre. Y no sólo que aumentó la extensión sino que definió su forma. Es como si dijéramos que de súbito se agranda y cambia de forma aquello que habíamos concebido como pequeño y como plano. Los dogmas científicos sobre el particular sufren una aparatosa sacudida $y$ se derrumban. Este mundo reducido de nuestra concepción había sido ridículamente pequeño. Los fundamentos pretensiosos de nuostra ciencia no habían sido ciertos. El mundo $Y$ sus dones no estaban circunscritos a esta ínfima parcela conocida. Existía, en medio de los "mares tenebrosos", un mundo nuevo, quizás un mundo mejor, donde también habian seres humanos, quizás más felices. Nuestra sabiduría de siglos ignoraba toda esta maravilla. Y, entonces, el Mundo Europeo, que había vivido de espaldas a esta tierra desconocida, cambió de 
mentalidad, tuvo una nueva visión, una enorme persepctiva para su inteligencia asombrada y una nueva concepción del universo y de la vida.

\section{Una nueva Concepción del Mundo}

Como los grandes acontecimientos de la Historia; como la invasión de los bárbaros sobre el mundo civilizado de Occidente, que parecía derrumbar la cultura, pero que hizo resurgir de esta misma levadura ctra renovada; como la Revolución Francesa, que proclamó una nueva forma de Derecho, de Estado y de Gobierno para todos los pueblos del Mundo; como los inventos del vapor, como el descubrimiento y la aplicación de la energía eléctrica; como, en los actuales momentos, el descubrimiento de la energía atómica, que cambiará la filosofía, la praxis y el destino humano, el descubrimiento de América revolucionó el pensamiento europeo, cambió su orientación, reajustó su sistema filosófico y le llevó a una nueva concepción del Mundo.

En lo material, en lo espiritual, en lo cultural, en lo religioso, en lo moral, en lo económico y jurídico; en todos los aspectos del pensamiento y en todas las direcciones de la acción, América tuvo una gran resonancia, con enorme virtualidad para modificar las afirmaciones tenidas como invariables. Surgío una nueva problemática para la Filosofía y las Ciencias, para la Religión y el sistema económico de los Gobiernos; para la ciencia de la navegación y para las artes de la conquista; para los estudiosos de los secretos de la naturaleza y para los preocupados en los problemas del hombre; para los espíritus aventureros y para los ambiciosos de riqueza; para todos hubo un mundo inmerso, cuyas cortinas "tenebrosas" se habían rasgado. Pero no se proyecta sobre el pensamiento europeo sólo como un campo virgen para las explotaciones. América proyecta también sobre Europa su personalidad esencial, su espíritu objetivo, su cultura, sus instituciones, sus formas de gobierno, sus sistemas de vida. No era un mundo bárbaro capaz sólo de ofrecer riquezas a raudales; tierras de más o menos fácil apropiamiento; hombres para el trabajo y la servidumbre. Era más bien, un mundo de cultura propia y avanzada, con gobiernos socializados, con pueblos que gozaban de bienestar. Y esto repercutió en forma intensa en los] sociólogoseleuropeos, y equellos que tenían el alma teñida de emoción social y profesaban el amor de la justicia entre los hombres. Para ellos, para estos utópicos del Renacimiento, parece que estaba en Ámérica la República de Platón.

\section{El Continente de las Ulopías}

Lo que acabamos de decir tiene su expresión concreta en los utopistas de los siglos XVI y XVII. Las "repúblicas imaginarias" de estos espíritus apostólicos tienen su raíz y su estructura en las "repúblicas reales" de la América precolombina: en los estados reales del Continente Indo, mucho antes que Américo Vespucio recorriera las bocas del Amazonas y del Orinoco. Por eso, es indiscutible que la Utopía de Tomás Moro, la Ciudad del Sol de Campanella y, aún, la Nueva Atlántida de Bacon tienen su no declarado escenario en los países indos, podría decir: pre-americanos. Y, algo más, la maravillosa oragnización del Imperio de los Inkas, su economía socializada, su gobierno paternal, sus leyes enérgicas pero con fines comunales, su admirable sistema de trabajo, etc., fueron las fuentes reales que inspiraron a aquellos filósofos socialistas, la construcción de sus gobiernos arquetipos. 
Tomás Moro, se puede afirmar que declara que las exploraciones de Américo Vespuscio, que la publicación de sus Mundus Novus, fueron la base para su Utopía. Su personaje central, Hitlodeo, comienza por decir que dejó su patria, Portugal.... "Y en eu deseo de conocer nuevas tierras, juntóse a Américo Vespucio, del que fué compañero inseparable en los tres últimos de los cuatro viajes; mas no regresó con él en el postrero. sino que solicitó y abłuvo de Américo, casi por la fuerza, ser uno de los veinticuatro que se quedaron en una ciudadela situada en los confines alcanzados en dicho viaje'. Al leer la Utopía, se encuentra a cada paso, los motivos tomados de la descripción hecha por Vespucio, conforme a las relaciones obtenidas de la organización del Tawantinsuyu en las tierras que descubrió. Dice Vespucio.... "Viven sin rey y sin ninguna clase de soberanía y cada uno es su propio dueño"... y agrega en otro lugar.... "Los pueblos viven con arreglo a la naturaleza y mejor los llamaríamos epicúreos que estci$\cos \ldots$ "No tienen propiedad alguna sino que todas son comunes"... Âsimismo da la noticia de que no tienen moneda y que desprecian el oro, que usan sólamente para cosas sagradas u ofrendas funerarias.

Este es un pasaje de Utopía, que nos ilustra bastante:... "Hay una ocupactón, la agricultura, común a hombres y mujeres y que nadie ignora. Enséñasele a todos desce la infancia, en parte por medio de reglas aprendidas en la escuela $\gamma$ en parte llevándolos como por entrenamiento, a los campos próxinis".... Y esia es una ocupasión por excelencia del Inkanato.... "A parte de la agricultura, que como he dicho, es común a todos, se instruye a cada cual en una profesión propia, tal como el beneficio de la lana, el arte de trabajar el lino o los oficios de cantero"... Podemos seguir citando.... "La principal y casi única misión de los Sifograntes (Magistrados subalternos) es procurar $y$ prever que nadie esté ocioso y que cada cual se consagre con puntualidad a su oficio, sin llegar a fatigarse".... "Los magistrados jamás obligan a los ciudadanos contra su voluntad al ejercicio de tareas inútiles"... "El discreto se admirará menos de que el uso del oro y de la plata se acomode a sus costumbres mejor que a las nuestras. Electivamente, como desconocen la moneda, reservan aquellos metales sólo en previsión de acontecimientos que pueden Co no sobrevenir. El oro y la plata (de donde la moneda se fabrica), no tiennen entreuellos más valon que ebmaterial".

Históricamente, se prueba que Américo Vespucio hizo sus viajes en los primeros años del siglo XVI y la primera edición latina de Utopía fuś en 1516. Por otra parte, Eugenio Imaz, comentarista del Libro "Utopías del Renacimiento", dice: "Por entonces Américo Vespucio descubría el Nuevo Mundo a los europeos. La presencía de Ámérica ha hecho surgir la Utopía, ha hecho posible el viaje de Hitlodeo, compañero inmaginario de Américo". Y el Dr. Luis E. Valcárcel sostiene, por su parte, "No resulta del todo infundada la hipótesis de un conociniento del Perú por los europeos antes de la llegada de Francisco Pizarro"... "En Panamá y Darién desde mucho tiempo atrás se sabía de la existencia de un país de las extraordinarias características del Perú y es muy probable que las mismas noticias recibieran los europeos que con Américo Vespucio llegaron a las costas del Brasil apenas principiado el siglo XVI. ¿Cómo iban a ignorar los habitantes de las bocas del Amazenas de la existencia del Tawantinsuyu?".

En cuanto a Ciudad del Sol de Campanella hay, igualmente, fundadas razones para sostener que el Tawantinsuyu fué su modelo, $Y$ los descubridores de esta raíz histórica han sido sociólogos extranjeros. Aparte de que los datos e informaciones para CampaneIlla son ya más abundantes. Por esa misma época Garcilaso escribía y publicaba sus Comentarios Reales. Ya se habían publicado también multitud de Crónicas sobre la Conqulsta del Perú, tanto en español como en italiano. Dice De Greef:... "La Crónica de Pe- 
dro Cieza de León se publicó por primera vez en Amberes, 1554, y fué traducida al italiano y publicada en Roma en 1555 y en Venecia en 1560. Esta última edición es la más completa.... Campanella debió tener conocimiento de ello, ya que indudablemente estuvo en relación con numerosos españoles e italianos que regresaron de aquellas comarcas, y cuyos relatos, por lo demás, corrían de boca en boca". Otro autor, Lafargue, atribuye tambión a Campanella haber conocido el sistema inkaico. El mismo Campanella se refiere en sus obras al descubrimiento del Nuevo Mundo.

A través de la lectura de la Imaginaria Ciudad del Sol se encuentran las notas similares a las del Imperio del Tawantinsuyu. El ceremonial que acompaña al cultivo de la tierra; la ubicación geográfica de la Ciudad que está entre el actual Ecuador y el $\mathrm{Pe}$ rúi que nadie reciba más de lo que merece, pero que tampoco le falte nada de lo necesario; la división del trabajo por sexos y edades; las mujeres hilan y preparan las comidas; no se aprecia ni el oro ni la plata, sólo sirve para vasos ornamentales; se casa a los deformes y a los tarados entre sí (Esto queda bien establecido en la Nueva Corónica de Guamán Poma de Ayala)... "La comunidad hace a todos los hombres ricos y pobres al mismo tiempo, porque todo lo tienen: ricos porque todo lo tienen; pobres, porque nada poseen y luego no sirven a las cosas sino que las cosas les obedecen a ellos".

Es conveniente hacer notar que las influencias de los reynos de América pre-colombina sobre estas utopías tienen un límite preciso, en lo que corresponde a los elementos culturales trasplantados, que forman el esqueleto de dichas obras; existen también mucho de las rpúblicas idealistas de Platón o de la Ciudad de Dios de San Agustíni igualmente, mucho de los fundamentos téricos de las sociedades perefctas, que devanaban los sesos de estos ideólogos, en medio de unas naciones y unos estados descompuestos y oligárquicos.

También, es curioso que en tiempos de la Colonia, algunos españoles quisieron hacer la revivencia de los gobiernos primitivos de América, pero ya como una aplicación de las Repúblicas Utópicas de Tomás Moro o de Campanella. Tenemos el ejemplo de Vasco de Quiroga en México y de los Jesuitas en el Paraguay. Benedetto Croce, que regatea un poco la influenciar del Tawantinsuy̆ en lavebraode Campanella, sí cree en el modelo de la Ciudad del Sol para la obra de los Jesuitas.

En lo referente a Nueva Atlántida de Francis Bacon, publicada en 1627, dos años después que la Ciudad del Sol, basta decir cómo comienza la obra para establecer la vinculación con el pueblo de los Inkas.... "Partimos del Perú, donde habíamos perma. necido por espacio de un año. rumbo a China y Japón, cruzando el mar del Sur".... "pudiera ser que hubieran islas o continentes que hasta ahora no habían salido a luz...... y al amanecer del día siguiente pudimos distinguir que a nuestra vista se extendía una tierra llana"... He subrayado las frases tan significativas con que empieza Bacon a esbosar el plan de su obra, para encontrar muy pronto el continente que todavía no había salido a luz.... Por otra parte, la Nueva Atlántida, si bien tiene esta clara relación con el Perú de los Inkas, o más bien del Coloniaje, se aleja bastante de la concepción socialista a la antigua. Ya aparecen, con suma profusión, los elementos modernos de la civilización.

\section{Un nuevo Campo Polémico sobre los Derechos Humanos}

Es muy sabido que con motivo del descubrimiento de América y de la conquista de estas tierras por los hombres de España y Portugal, en nombre de sus Reyes y en nombre de la Religión Cristiana, se suscitaron diversas concepciones sobre el aspecto huma- 
no de los habitantes de estas Indias. El Papa concedió a los Reyes el derecho de conquistar y repartirse la stierras descubiertas, encomendándoles la salvación de las almas de estos "buenos salvajes". Los Reyes adoptaron actitudes fraternales para con estos pobres indios, en el terreno de las disposiciones $y$ de las leyes, pero, ni ellos tuvieron la real intención de protejerlos, ni sus "encomenderos" se preocuparon por amparar verdaderamente a estos infelices, que "les partía el corazón" de emoción piadosa, pero que bien les servía de esclavos hasta derramar su última gata de sangre y sudor. Los Reyes de entonces siempre dieron muestras de profundos escrúpulos de conciencia, como aparecen en los considerandos de las Leyes de Indias; pero sabían también absolverse rápidamente de estos remordimientos con resoluciones equívocas que nadie cumplía, y todo quedaba en el papel. De aquí que surgieron opuestos criterios doctrinarios sobre la personalidad humana de los indios de Āmérica. Unos, crueles e inhumanos, como Sepúlyeda, Capellán de Carlos V, que sostenían que los salvajes de América eran seres infeiores, bárbaros temible y peligrosos, fuera de los alcances de las bondades cristianas, que merecían un trato duro $y$ enérgico, sí es posible para exterminarlos; que no debía legislarse sobre ellos, puesto que eran poco más que animales. Otros, como el célebre Padre Vitoria, que rompió lanzas en discusiones memorables sobre la humanidad y los derechos del hombre de América. Entre estos apóstoles infatigables se cuenta al Padre Las Casas, que dedicó su vida, su ingenio y su valor, a convencer a los sañudos consejeros de los Reyes, sobre la condición humana de los indios, sobre la necesidad de am. pararlos y protejerlos de la voracidad insaciable de los conquistadores.

El Imperio Socialista de los Inkas llamó tanto la atención en el pensamiento europeo, que la literatura del siglo XVII y XVIII se llenó de motivos inkaicos. Voltaire to. mó para una de sus piezas de teatro: "Alzira", un argumento que tiene lugar en la tiera del Tawantinsuyu. "Las Cartas de una Peruana", de Madama de Graffigni, relatan la historia de amor de dos personajes idílicos que se comunican por quipus. Marmontel escribe una novela sentimental que muestra un imperio amabie y risueño, a la manera de la Nueva Eloísa de Rousseau. Hay tantísimos autores que hacen el análisis sociológico del Imperio de los Inkas, con diferentes criterios; historiadores apasionados que agotan la tesis y la antítesis, quedando un balance favorable es indestructible del glorioso pueblo de Manco, que forjó una cultura, en donde el trabajo bien distríbuido y la riqueza bien dirigida y mejor repartida, fueron capaces de labrar el bienestar y la felicidad de todos sus habitantes.

En la misma forma se observa la resonancia de la América procolombina en los círculos artísticos de Europa, por la grandeza de las construcciones, por la belleza imponente de sus monumentos y por la singular personalidad de su arte creador, de los Aztecas y los Mayas, al igual que de los Inkas. Seguramente llenó de. asombro a los euro peos la descripción que hace Hemán Cortés de la ciudad de Tenochtitlán, tan populosa, tan llena de mercados $y$ de movimiento comercial intenso, como la mejor de las ciudades de entonces del Occiplente. Pueblos que edificaron templos y ciudades tan grandiosos, que concibieron religiones superiores y gobiernos de auténtica finalidad popular, no podian quedarse en la conmiserativa calificación de "buenos salvajes".

\section{Nuevos Horizontes para el Pensamiento Científico}

El descubrimiento de América abre un ancho campo a las investigaciones científicas, sobre todo para las elucubraciones de carácter naturalista. A través del seiscientos y del setecientos, se estudia y se discute sobre el continente y la naturaleza del Nuevo Mundo. 
Sabios naturalistas y filósofos dedican sus reflexiones sobre las cosas de este lado del mar. Opiniones contradictorias emiten estos hombres de ciencia sobre las peripecias geológicas y biológicas de esta sarandeada Indoamérica.

"Este lado inmaturo de la tierra"... produce hombres desnudos como Adán antes de comer la manzana... dice Donne en 1597. El célebre Buffon - de quien dice Vargas Vila: el más animal de los poetas a fuerza de ser el más poeta de los animales - se pronuncia sobre la inferioridad y la debilidad del Nuevo Mundo. Para él todo es pequeño en América, hasta las fieras; el león no es propiamente león, "es mucho más pequeño, más débil, más cobarde'. No hay aquí Elefantes, Hipopótamos, Camellos, ni Rinocerontes. Todos los animales traídos de Europa se han achicado. Resulta, pués, que el ambiente americano es hostil al desarrollo de los animales. Para el Padre Raynal, que publica su obra en 1770, los americanos ni siquiera tienen barbas. El abate De Pauw se pronuncia francamente contrario al hombre de América. No cree en las perfecciones de que hablan Garcilaso y Las Casas. El Cusco fué para él un hacinamiento de chozas, y los Amautas ignorantes que no sabían leer ni escribir enseñaban a otros ignorantes que no sabían hablar. Todo está envilecido, disminuído. degenerado para De Pauw en Amórica.

Así hubo un brote enorme de científicos que hicieron la impugnación y la defensa de la naturaleza de América. En estas mismas tierras surgieron grandes defensores y reivindicadores de la grandeza del Nuevo Continente, que no es inmaturo ni inferior, y que no merece ser estudiado desde el punto de vista Europeo, sino desde el plano de América. En el siglo pasado hubo un gran filósofo, Hegel, que revivió la tesis de la América inferio: e impotente. Igualmente, De Maistre y Schlegel se sumaron a los filósofos historicistas que esgrimen el principio de la infancia, de la imperfección, de la falta de vigor físico en sus habitantes. Pero la Historia del siglo XX está probando, hasta la saciedad, la robustez y la plenitud vital de América, que siempre tuvo estas caractorísticas, desde que se forjaron la cultura de la papa y la cultura del maíz, y se ofrendaron al mundo, como regalos imponderables para su sustento.

\section{Biblioteca de Letras “Jorge Puccinelli Co Jullo Cósar Pozo.}

\section{Obras coneultadas:}

LAS UTOPIAS DEL RENACIMIENTO.- Fondo de Cultura Económica, México. VIEJAS POLEMICAS SOBRE EL NUEVO MUNDO:- Antonello Gerbi, Lima. FUENTES DE LA HISTORIA DEL PERU.- Copias de 1945, Raúl Porras Barrenechea. LAS UTOPIAS Y EL PERU DE LOS INKAS.- Artículo publicado en la Prensa, 12 de diciembre de 1943, Luis E. Valcárcel. 